\title{
SOBRE O ENSINO DA DANÇA: ALGUMAS CONSIDERAÇÕES SOBRE A PEDAGOGIA DO MOVIMENTO ${ }^{1}$
}

\author{
Milton de Andrade ${ }^{2}$ \\ Diogo Vaz Franco Santiago ${ }^{3}$
}

\section{RESUMO}

A pesquisa que deu forma a este artigo propõe uma releitura de alguns nomes e teorias novencentistas da dança moderna, e de estudiosos do movimento, para se pensar uma pedagogia que dialogue com práticas contemporâneas compositivas e de ensino da dança. $\mathrm{O}$ objetivo é apontar um viés de pensamento sobre o ensino de dança pautado na análise das dinâmicas do movimento humano, na relação entre mente e corpo e nas teorias da aprendizagem.

Palavras-chave: dança moderna, corpo-mente, pedagogia, movimento, teoria

${ }^{1}$ Projeto de Pesquisa "RITOS DA METAMORFOSE CORPORAL:

ENTRE A DANÇA, A DRAMATURGIA DO CORPO E A PSICOFÍSICA DO ATOR” UDESC - Centro de Artes.

${ }^{2}$ Orientador, Professor Doutor do Departamento de Artes Cênicas - Centro de Artes - UDESC. deandrade@tin.it

${ }^{3}$ Acadêmico do Curso de Artes Cênicas - Centro de Artes - UDESC, bolsista de iniciação científica do PROBIC/CNPq. diogovfs@yahoo.com.br 


\section{SOBRE O ENSINO DA DANÇA: ALGUMAS CONSIDERAÇÕES SOBRE A PEDAGOGIA DO MOVIMENTO}

Este artigo pretende levantar reflexões sobre formas de pensar um ensino de dança que se empenha não apenas na organização estética da linguagem e na execução de padrões convencionados dos estilos de dança, mas que também abre campos de visão para se trabalhar sobre "a pessoa que dança", sobre o funcionamento orgânico do corpo que dança e a percepção cinética durante este ato. Neste sentido, o objeto deste estudo não é somente a dança, mas o movimento em toda a sua complexidade.

Para tanto, são trazidos para esta reflexão alguns importantes pesquisadores do trabalho sobre o movimento humano como Isadora Duncan (1877 - 1927), Rudolf von Laban (1879 - 1958), Klauss Vianna (1928 - 1992) e Moshe Feldenkrais (1904 - 1984). São pesquisadores que durante o século XX promoveram teorias sobre o ensino da dança e desenvolveram métodos próprios de se trabalhar o corpo em movimento.

Até o início do século XX, o balé clássico imperava nas salas de ensino da dança. Este era um método quase único na pedagogia da dança. No contexto brasileiro, este período se estende até metade do século passado, e a dança moderna vem como forma de criar outro espaço e uma nova filosofia para a dança.

$\mathrm{O}$ que mais incomodava os reformadores do início do século XX era não somente a estética da dança enquanto espetáculo, mas também sua didática de ensino.

\footnotetext{
O método didático da dança clássica caracteriza-se por: demonstração, imaginação e imitação e por incansáveis repetições. Da parte do aluno requer-se sobretudo confiança e veneração incondicionais para com o mestre. Da parte do professor fazese necessária uma consciência de responsabilidade, paciência e sensibilidade para com a individualidade do aluno (WOSIEN, 2000: 73).
}

Este era um pensamento que não era mais aceito pelos artistas daquela época. Vê-se que os objetivos da dança clássica estavam totalmente voltados à perfeita execução de uma técnica secular para perpetuar uma das tradições mais bem sucedidas da história das artes. E isso era um sinônimo de aprisionamento para os reformadores modernistas. "Nos primórdios da dança moderna, seus cultores não tinham outra idéia em mente além de sua própria liberação" (FARO, 1986: 117).

No século XVIII, Jean-Georges Noverre (1727 - 1810) propõe no balé de corte um movimento de "restauro", num certo sentido, semelhante ao que os artistas da dança moderna propunham em relação à tradição clássica oitocentista. Ele aboliu da dança toda a 
espetacularidade que os objetos e figurinos propunham no 'balé de corte' barroco. Sua intenção era focalizar a ação cênica no corpo do bailarino, no movimento gestual. A busca do movimento expressivo fez com que Noverre criasse o 'balé de ação' e abolisse todo e qualquer ornamento que impedia o livre fluxo dos movimentos. E "livre fluxo do movimento" é a expressão-chave para certos reformadores modernos da dança como Duncan e Laban.

Com uma estética toda particular e inovadora, Isadora Duncan trabalhou sobre o bailarino e sua entrega ao movimento de forma mais espontânea. Para ela, o fluxo natural do movimento estava totalmente relacionado a algo de subjetivo; portanto, buscar organização e organicidade no movimento dançado significava trabalhar uma dimensão interior, com as paixões e as emoções de cada dançarino.

Se Noverre aboliu os adornos de cena e a virtuose barata, Duncan foi mais a fundo: renovou a própria idéia de técnica. Ao propor uma dança improvisada, de movimento livre, ignorou totalmente os preceitos clássicos de sua época.

Laban foi fortemente influenciado pelo espírito de libertação e experimentação do qual Duncan foi pioneira, mas não seguiu a risca seus passos. É preciso destacar que ele propõe, para além de uma dança livre, referenciais corporais que instrumentalizam o processo criativo e o tiram da qualidade de trabalho espontaneísta. Tais referências acabam por possibilitar um maior grau de consciência corporal nas experimentações de movimentos. Para Laban, experimentar significa "tentar fundar uma prática e uma teoria do movimento, como experimentação e saber, para que uma corporeidade inédita surgisse" (LAUNAY, 1999-2001: 76).

Quando falamos de dança livre, movimento liberado, fluidez e natureza do movimento, conforme Laban, falamos de uma proposta de dança que também requer uma técnica. Esta nova proposta de pensar a dança exige uma técnica e uma didática específica que, dentro da filosofia moderna, estimula o domínio do movimento em todos os seus aspectos corporais e mentais. Pela proposta de Laban, “em vez de estudar cada movimento particular, pode-se compreender e praticar o princípio do movimento. Este enfoque da matéria da dança implica uma nova concepção desta: o movimento e seus elementos" (LABAN, 1990: 16).

A dança criativa surge como alternativa para aquelas danças, ou aulas de dança, cuja estrutura define-se basicamente por "[...] aprender movimentos codificados e rígidos, sem qualquer interferência pessoal no que diz respeito à criação do 'passo' ou do movimento executado" (MARQUES, 1999: 81). Esta idéia de que o movimento deve ser estudado e trabalhado não a partir de referencial externo dado por uma técnica estilística ou uma 
linguagem desenvolvidas, mas sim a partir das próprias condições orgânicas do indivíduo que se movimenta, encontra também fundamento nas proposições para o trabalho de consciência corporal de Feldenkrais.

Feldenkrais foi um renomado físico e atleta - o primeiro judoca europeu a receber faixa preta - que, ao receber um diagnóstico de que devido a sucessivos problemas no joelho não poderia mais caminhar, resolveu usar seus conhecimentos de física e do corpo humano para encontrar um modo de recuperar o uso das pernas. Como resultado de seu empenho, em dois anos já estava andando e resolveu prosseguir com seus estudos e investigação sobre a profunda ligação entre cérebro e corpo. Assim, Feldenkrais desenvolveu mais de mil exercícios com o objetivo de reabilitar e melhorar os centros cerebrais de aprendizado do movimento. "Seu método atua nas habilidades e ações cotidianas, como andar, sentar etc., adquirindo e/ou aprimorando-as, pela diferenciação" (MÁLIKA, 2008: 1), facilitando o reconhecimento de todas as partes do corpo que se empenham para fazer acontecer o movimento, inclusive aquelas que não imaginamos. O movimento é, então, profundamente sentido e compreendido e esse aprendizado leva a uma mudança na base motora, ou seja, no modo como o indivíduo realiza determinada ação. Os resultados são a melhora da qualidade dos movimentos já executados e o aumento do repertório de movimentos.

Segundo Feldenkrais, cada pessoa se move distintamente de acordo com a autoimagem que constrói ao longo da sua vida. Segundo o autor, "nós agimos de acordo com nossa auto-imagem. Esta, que, por sua vez, governa todos os nossos atos - é condicionada em graus diferentes por três fatores: hereditariedade, educação e auto-educação" (FELDENKRAIS, 1977:19).

A nossa auto-imagem nunca representa todo o nosso potencial. Nossa auto-imagem é menor que a nossa capacidade potencial. As poucas pessoas que se destacam da média não são pessoas excepcionais e de grande potencial, são pessoas cuja imagem pessoal compreende uma parte maior do potencial que é igual a todos. "Uma auto-imagem completa envolveria plena consciência de todas as articulações da estrutura do esqueleto, bem como da superfície interna do corpo - costas, lados, entrepernas, e assim por diante; essa é uma condição ideal e consequentemente rara" (FELDENKRAIS, 1977: 39). Acontece que as pessoas não são totalmente conscientes do corpo que têm. Elas só percebem mais nitidamente as partes que utilizam cotidianamente, enquanto que as menos utilizadas ou secundárias no padrão de movimento habitual são esquecidas pela nossa auto-imagem. Por isso, é que a mudança de nosso padrão de movimento envolve não somente a transformação de nossa imagem 
pessoal,“[...] mas uma mudança na natureza de nossas motivações e a mobilização de todas as partes do corpo a elas relacionadas" (FELDENKRAIS, 1977: 27).

Todas estas colocações de Feldenkrais a respeito da auto-imagem servem para demonstrar um caminho eficiente para o trabalho com o movimento e com o corpo. Trabalhar com a imagem pessoal e não com ações particulares: essa é uma forma de corrigir os problemas por completo e não atuar por medidas provisórias. Esta diferenciação é fundamental para pensar o processo de aprendizado da dança. Seguindo o pensamento de Feldenkrais, este aprendizado deve ter como foco principal a própria pessoa, num movimento reflexivo que é voltado para as sensações e para as respostas que o corpo dá, de forma que a mente possa atuar em conjunto a essa máquina que é o corpo humano, e não o inverso.

Trabalhar sobre a imagem pessoal é deixar o corpo estimular a mente, sendo o conhecimento tido como algo que já está no aprendiz, em alguma dimensão de seu corpo. $\mathrm{O}$ trabalho do professor seria o de proporcionar e criar condições para o aprendiz ter maior contato com seu próprio corpo em movimento e descobrir como ele funciona e se organiza espacialmente no contexto da dança. Klauss Vianna usa a expressão "parteiro" para se referir ao trabalho do professor: "O professor é um parteiro, ele tira do aluno o que ele tem para dar. Se o aluno não tem nada, não sai nada" (VIANNA, 1990: 34).

Para esclarecer esta relação aprendiz-professor, podemos citar a estudiosa da área da didática Amélia Domingues de Castro, que, em seu texto $O$ ensino: o objetivo da didática (2002), aponta duas tendências da relação ensino-aprendizagem que podem abrir o nosso campo referencial sobre o tema:

a) o ensino é concebido como algo que vem de fora para dentro (posição exógena),
como a entrega de bens culturais aos alunos, pela sociedade e seus representantes: os
educadores. Corresponde a idéia de 'passar' ou 'transmitir' algo ao aluno, que a
linguagem comum aceita na popular idéia de 'dar aula' (doar, entregar).
b) o ensino é concebido como algo que vem de dentro para fora, dependendo apenas
de alguns poucos referencial externos. O protótipo histórico é o platonismo e a idéia
socrática de maiêutica, que assemelha a função docente a da parteira, pois ajuda a
dar à luz as idéias. Anacrônica e oferecida apenas como ilustração, essa posição
teoricamente inatista tem seu contraponto moderno naqueles que recusam a primeira,
entendendo que ensinar é impossível, já que, como diz Carl Rogens '.... u única
aprendizagem que influencia significativamente o comportamento é aquela que foi
autodescoberta, auto-apropriada' (CASTRO, 2002: 22).

Esta segunda concepção de ensino tem estreita relação com os preceitos modernos de dança educativa. E as palavras de Carl Rogers (1902 - 1987) poderiam ser perfeitamente iguais às de Rudolf Laban ou Klauss Vianna. A concepção de aprendizado na dança clássica se aproxima mais da primeira tendência exposta por Castro, que concebe o professor como o 
mestre detentor do conhecimento e do aluno como o 'ser sem luz' que precisa de um mestre para poder aprender "a lei do movimento esclarecido" (WOSIEN, 2000: 87).

A dança clássica tem uma estrutura extremamente hierárquica que transparece na metodologia de seu ensino. Klauss Vianna reflete sobre a relação entre professor e aprendiz no balé clássico. Fala que esta característica militar de disciplina não dá espaço para o sentir, só para o repetir. Este tipo de relação não traz o aluno para dentro da aula, ou melhor, para dentro de si, mas o deixa aparte a tudo isso e o seu objetivo é apenas acertar. "A sala de aula, dessa forma, se torna apenas uma arena para competição de egos, onde ninguém se interessa por ninguém a não ser como parâmetro para competição" (VIANNA, 1990: 25).

No trabalho corporal, quando se traçam objetivos que são externos a nós, prioriza-se este determinado fim e os corpos acabam transformados em meros instrumentos para atingir esse objetivo externo. Corpo e mente estão voltados para a aproximação do modelo ideal. Nestes casos, a ação por conhecimento acaba se tornando reprodução por imitação. Isso tem a ver com auto-imagem se trouxermos para a discussão a definição de Henri Wallon (18791962), psicólogo que estuda a relação entre o movimento corporal e a atividade mental, à respeito da imitação: "[...] operações complicadas que pressupõem o conhecimento ou a imagem de um modelo, a capacidade de ajustar a esse modelo os seus próprios gestos e utilizá-los como recurso para atingir pessoalmente objetivos tidos como semelhantes aos que ele tem em mira" (WALLON, 1995: 55).

Muitas pessoas com esse tipo de determinação acabam forçando física e psicologicamente um processo que requer tempo e tranqüilidade, disciplina e organização. Disciplina e organização,algo que o indivíduo resolve consigo mesma numa relação íntima com seu corpo. Organizar é organizar-se. Disciplina é respeito consigo mesmo. Esse é o caminho para se criar uma dinâmica corporal que converte e torna fluente e natural todo gesto, que transforma o aprendido num hábito e "que assimila e ao mesmo tempo transcende os limites do próprio aprendizado" (VIANNA, 1990: 85). Ninguém melhor do que a própria pessoal para organizar o nosso corpo. Esse não é o trabalho do professor. O aprendiz deve poder reconhecer os processos interiores do movimento, compreender cada músculo, cada articulação.

Toda técnica de dança parte de uma forma de movimentação específica. Ela seleciona determinados tipos de movimentos e trabalha para a aquisição daquela lógica corporal particular. Por um lado, isso faz com que a pessoa, aluno ou bailarino, alcance um alto grau de desenvolvimento daquela forma de dançar, porém acondicionar no corpo uma única 
possibilidade de exploração dos movimentos que ele é capaz de executar e de criar é um ônus nem sempre justificável.

$\mathrm{Na}$ dança educativa, os esforços dirigem-se para dotar o corpo da capacidade de relacionar-se consigo mesmo em sua incalculável variedade motora. Para tanto, torna-se impossível partir de um estilo idealizado segundo normas específicas. É por isso que Rudolf von Laban propõe uma técnica de dança livre. "Precisamos empregar todo o nosso ser no material do movimento e descobrir a facilidade ou dificuldade que temos para utilizá-lo e maneja-lo ao dançar. Isso nos dará maior compreensão de nós mesmos e nos estimulará a desenvolver nosso potencial" (LABAN, 1990: 114-115).

Sobre este desenvolvimento do potencial de que Laban fala, podemos usar as idéias de Moshe Feldenkrais para dizer que existem três estágios no processo de desenvolvimento das atividades humanas. O primeiro estágio é o natural, o segundo é o individual e o terceiro, o sistemático. As atividades naturais são aquelas que fazemos desde criança, com espontaneidade, sem um prévio treino ou instrução a respeito. Andar, brincar, comer, pegar, sentar. O segundo estágio é quando nós definimos uma forma específica de fazer as coisas e adotamos esta como a melhor forma; quando encontramos um modo pessoal que melhor convém de executar tal ação. O terceiro estágio se dá quando as atividades são executadas segundo um método, uma forma que foi racionalmente pensada para fazer tal tarefa. Neste estágio a ação tem tais características devido a estudos e pesquisas.

Cada pessoa adapta-se ao estágio que julga mais eficiente. Alguns vão preferir agir instintivamente, outros desenvolverão um jeito pessoal enquanto outros recorrerão a métodos externos para alcançar o desejado. "Em muitos casos, é difícil dizer se poderíamos confiar no método natural ou se é melhor começar do início e estudar os estágios metódicos" (FELDENKRAIS, 1977: 46).

$\mathrm{O}$ terceiro estágio tem suas vantagens e desvantagens. Uma vantagem é que ele possibilita encontrarmos diferentes formas de lidar com as situações nas quais o espontaneismo e a naturalidade não encontram espaço para se desenvolverem. "Estudos sistemáticos e consciência poderiam prover os homens com os meios de explorar todos os meios de ação e, assim, encontrar um lugar para si” (FELDENKRAIS, 1977: 47). Porém, aí pode existir uma desvantagem: "Quando os movimentos são preestabelecidos por um repertório técnico, o corpo executa o que já está mapeado pelo cérebro” (MUNIZ, 2001: 29). Maria Izabel de Carvalho e Muniz, estudiosa das propostas educacionais da dança de Klauss Vianna, aponta que aquele que dança somente seguindo um repertório técnico específico está limitado a estas referências estéticas de movimento. Através das reflexões de Muniz sobre a 
técnica codificada e específica de uma lógica corporal, é possível chegar à conclusão de que este terceiro estágio de desenvolvimento não proporciona uma percepção orgânica e uma consciência funcional do corpo e do movimento na dança.

Klauss Vianna disse que "[...] um corpo inteligente é um corpo que consegue se adaptar aos mais diversos estímulos e necessidades, ao mesmo tempo que não se prende a nenhuma receita ou fórmula preestabelecida” (VIANNA, 1990: 113-114). Portanto, é preciso não só aprender a executar, mas principalmente também saber sentir. E este sentir é um "sentir de dentro".

Todo movimento exige um envolvimento ativo do sistema nervoso mais do qualquer outra coisa. Ele é sempre o resultado de um impulso nervoso e, deste modo, quando nos referimos aos movimentos musculares, estamos falando, antes deles, dos impulsos nervosos que são essenciais para o seu funcionamento. Muniz também pode contribuir para essa reflexão. Segundo a autora, "Possuímos um sistema nervoso que nos permite ter consciência do conteúdo energético e informativo do nosso corpo. [...] O sistema nervoso é capaz de perceber a informação contida no seu próprio corpo como também no corpo de quem ele observa.” (MUNIZ, 2002: 27).

Existe um conceito que trata justamente da percepção das sensações musculares através do sistema nervoso. Henri Wallon denomina este conceito de percepção tônicoemocional e Laban chama de sentido cinestésico. É sobre ele que a dança trabalha, da mesma forma que a música trabalha para aguçar a audição e as artes plásticas, a visão. Ele define-se por um conjunto de terminações nervosas situadas nas fibras musculares em todo corpo através do qual podemos perceber os esforços musculares, o movimento e a posição no espaço. $O$ sentido cinestésico tem fundamental importância no caminho para a autoconsciência e quando falamos de atentar-se ao sentido cinestésico ao dançar, estamos falando da percepção do sentido do movimento.

\footnotetext{
Desenvolver o sentido do movimento, do qual todos estamos dotados, em maior ou menor medida, é de suma importância. Para isso é necessária uma clara consciência das sensações motoras, combinadas com as que surgem da interação do esforço e do corpo no espaço. Os movimentos físicos que aparecem confusos no ritmo do esforço, as formas espaciais e a execução corporal não reforçam a sensibilidade para o movimento, nem a capacidade de criar no movimento. Deve-se aperfeiçoar o conhecimento da organização e o sentido da qualidade das unidades de movimento, com frequiência criadas livres e espontaneamente, de maneira que nossas ações físicas se tornem específicas o bastante para permanecer impressas em nós e se possa criar uma experiência psicofísica do movimento (LABAN, 1990: 109-110).
}

Pensar o sentido do movimento, a auto-percepção, a consciência total nos atos e a auto-imagem como princípio. Estas questões, que os pesquisadores modernos nos trouxeram no decorrer do século XX e que até os dias atuais ressoam nos ouvidos dos que ensinam 
dança, abrem espaços para pensar a arte do movimento como uma atividade pedagogicamente transformadora. Estas questões adaptadas àquilo que hoje se pensa e se pratica em dança são de grande valia para resgatar a noção de prazer pelo movimento. Um prazer que nasce não só por aquilo que se projeta no olhar de quem assiste, mas principalmente um prazer que acontece e permanece no corpo, devido ao respeito íntimo que se tem por ele e pelas sensações que um trabalho pautado na consciência cinestésica pode proporcionar a quem dança.

\section{REFERÊNCIAS BIBLIOGRÁFICAS}

CASTRO, Amélia Domingues de. O ensino: o objetivo da didática. In: Ensinar a ensinar. SP: Pioneira Thomson Learning, 2002.

FARO, Antônio José. A dança moderna. In: Pequena história da dança. RJ: Jorge Zahar Editor, 1986.

FELDENKRAIS, Moshe. Consciência pelo movimento. SP: Summus, 1977.

LABAN, Rudolf von. Dança Educativa Moderna. SP: Ícone, 1990.

LAUNAY, Isabelle. Laban, ou a experiência da dança. In: SOTER, Silvia; PEREIRA, Roberto. (org.). Lições de dança. Vol. 1. RJ: UniverCidade Editora, 1999-2001.

MÁLIKA. Um pouco da história de Moshe Feldenkrais e seu método de Educação

Somática. Disponível em: http://www.malika.com.br/artigo25.htm. Acesso em 02 jun. 2008.

MARQUES, Isabel A. As propostas educacionais de Rudolf Laban: um olhar contemporâneo. In: Ensino de dança hoje - textos e contextos. SP: Cortez, 1999.

MUNIZ, Maria Izabel de carvalho e. Um caminho traçado com arte: "Klauss Vianna" uma linha sobre a qual se dança. Florianópolis: UDESC, 2001.

VIANNA, Klauss; CARVALHO, Marco Antônio de. A dança. SP: Siciliano, 1990.

WALLON, Henri. As formas da atividade de relação - automatismo e representação. In: As origens do caráter na criança. SP: Nova Alexandria, 1995.

WOSIEN, Bernhard. A alta escola da dança clássica. In: Dança: um caminho para a totalidade. SP: TRIOM, 2000. 